\title{
Stability of North Atlantic Deep Water Formation in a Global Ocean General Circulation Model
}

\author{
S. B. POWER, * A. M. MOORE, * D. A. POST, * N. R. SMITH, * AND R. KLEEMAN* \\ * Bureau of Meteorology Research Centre, Melbourne, Australia \\ * *Centre for The Commonwealth Scientific and Industrial Research Organization, \\ Division of Atmospheric Research. Aspendale. Victoria, Australia
}

(Manuscript received 6 August 1992, in final form 16 August 1993)

\begin{abstract}
A global ocean general circulation model is forced using mixed boundary conditions (i.e., a restoring condition on the upper-level temperature but using a fixed, specified surface salt flux ). Freshwater flux anomalies lasting 5 years are then applied over the western half of the subpolar gyre in the northern North Atlantic.

The current climate is found to be stable to anomalies that have salt deficits equivalent to about seven times that estimated for the "great salinity anomaly" of 1968-1982, although this value is a function of the duration over which the anomaly is imposed. Above this level the thermohaline circulation collapses to a state in which the zonally averaged overturning associated with North Atlantic Deep Water formation is only about half its original value, the sea surface temperatures over the North Atlantic are lowered, and both the subpolar and subtropical gyres have weakened horizontal transports. Various atmospheric feedbacks on the momentum and salt flux are then applied under a restorative condition on temperature. The feedbacks on the momentum flux do not have a significant impact on the overturning, other than to increase the Ekman flow, while a modest recovery is possible if the salt flux feedback includes an enhanced divergence of freshwater out of the Atlantic basin.

In contrast, the collapse is critically dependent upon the restorative condition on temperature. This central role suggests that the heat flux feedback maintains the stability exhibited by the collapsed state modeled by Manabe and Stouffer.
\end{abstract}

\section{Introduction}

The importance of North Atlantic Deep Water formation (NADWF) in helping to maintain the current climate has been discussed by numerous authors (Semtner and Chervin 1988; Broecker et al. 1985; Broecker 1991). Because of this important role, recent studies have attempted to determine the stability of NADWF to various perturbations including freshwater flux anomalies imposed at high northern latitudes (Bryan 1986; Maeier-Reimer and Mikolajewicz 1989; Marotzke 1989; Wright and Stocker 1991; Stocker and Wright 1991; Stocker et al. 1992; Weaver et al. 1993). These results fueled an existing concern that NADWF could be halted if it became capped by low salinity water, thereby leading to a dramatic change in the ocean circulation (ICSUSCO 1991) and climate in general (Broecker 1991).

In most of these studies mixed boundary conditions (BCs), in which the salt flux is fixed and the heat flux is parameterized (after Haney 1971) in terms of deviations away from current climatic values of an apparent air temperature (or its proxy: sea surface tem-

Corresponding author address: Scott B. Power, BMRC, GPO Box 1289K, Melbourne, Victoria, 3001, Austratia. [sbp@bom.gov.au] perature) were employed. Under these conditions the meridional overturning associated with NADWF was found to be sensitive to freshwater perturbations, with seemingly small anomalies leading to states in which NADWF has collapsed. In this state far less heat is transported northward, thereby reducing the moderating influence of the ocean upon the regional climate.

This sensitivity should be contrasted to the observed response of the real ocean to the great salinity anomaly (GSA), which was a large freshening of the surface waters of the northern North Atlantic during 19681982 (Dickson et al. 1988). The GSA is believed to have been initiated by an anomalous outflux of sea ice from the Arctic into the North Atlantic subpolar gyre (Walsh and Chapman 1990) aided by anomalous regional northerlies (Dickson et al. 1988). There is also some evidence to support the idea that increased North American runoff into the Arctic basin may also have contributed (Mysak et al. 1990; Mysak and Power 1991).

There were substantial changes as a result of the GSA (Dickson et al. 1975), including possibly related oceanic changes (Greatbatch et al. 1991), but as far as we know, there have been no reports of a sustained collapse of the overturning associated with NADWF.

In this study we wish to determine if the sensitivity of ocean models to high latitude freshening extends to 

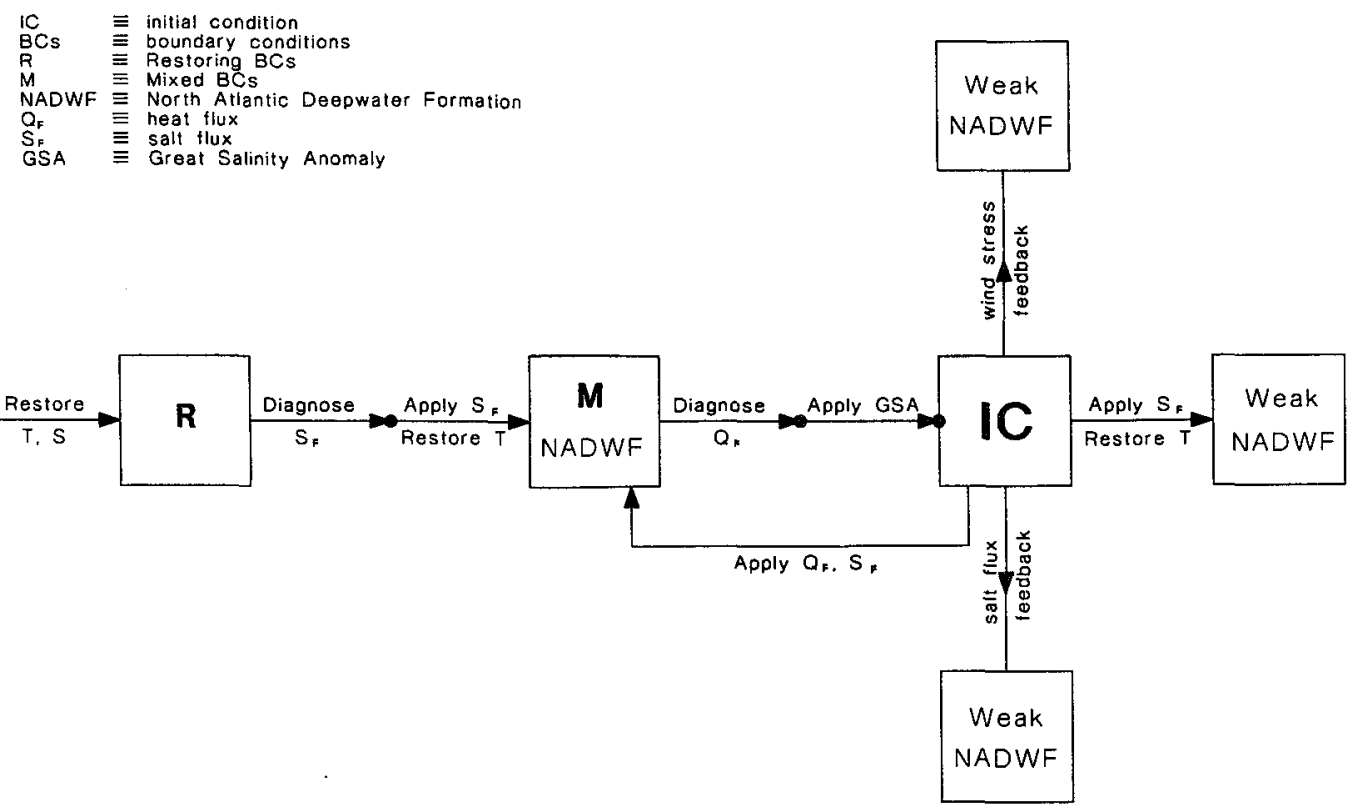

FIG. 1. A schematic representation of the experiments conducted.

a global ocean general circulation model (OGCM) with a more realistic representation of both bathymetry and continental geometry and to help quantify the sensitivity by determining the magnitude of the anomaly required to destabilize the current climate. We will find that there is a critical value above which the collapse will occur under mixed BCs.

We will then relax the constraint of fixed surface fluxes of salt and momentum by parameterizing anomalous fluxes in terms of the meridional temperature gradient of the sea surface temperature to see if the response is significantly altered.

The final aim of this study is to determine if the use of a restorative condition on temperature plays an important role in determining the response. The use of such a condition in studies of climatic change has been criticized (Power and Kleeman 1992) because it is strictly only a valid approximation for the heat flux in the current climate. It is therefore crucial to know if this choice of parameterization plays an important role in determining the stability of the system.

The OGCM used in this study is described in the following section. The results are presented in section 3 . The moderating impact of salt flux feedbacks and the dependence of the collapse upon the parameterization of the heat flux are discussed in section 4.

\section{Description of the ocean model}

The OGCM used here is the latest version of the Geophysical Fluid Dynamics Laboratory code (Pacanowski et al. 1991) based on the work of Bryan (1969) and Cox (1984) and given the acronym MOM (Modular Ocean Model).
The horizontal tracer grid was initially designed for coupling to an atmospheric model (Moore 1992, personal communication). It is an R21 Gaussian grid, which has a longitudinal spacing of $5.625^{\circ}$ and a latitudinal spacing of approximately $3.2^{\circ}$.

There are 12 vertical levels ranging in thickness from $25 \mathrm{~m}$ at the surface to $900 \mathrm{~m}$ in the deep ocean. The horizontal eddy viscosity is artificially large $\left(9 \times 10^{5}\right.$ $\mathrm{m}^{2} \mathrm{~s}^{-1}$ ) to ensure that the western boundary currents have horizontal scales that are resolved by the coarse grid. The horizontal eddy diffusivity is $2.5 \times 10^{3}$ $\mathrm{m}^{2} \mathrm{~s}^{-1}$. The vertical eddy viscosity and diffusivity take the same numerical values of $20,1.5$, and $1\left(\times 10^{-4}\right.$ $\mathrm{m}^{2} \mathrm{~s}^{-1}$ ) in the first, second, and subsequent levels, respectively, in order to crudely simulate a surface mixed layer. Further details regarding the configuration of this model are given by Moore and Reason (1993).

\section{Results}

\section{a. The preliminary experiments}

The preliminary experiments conducted are represented in Fig. 1 and differ only in the specification of the surface fluxes of momentum, heat, and salt. First the OGCM is integrated while restoring the upper-level temperature, $T$, and salinity, $S$, to annually averaged climatological values based on the data compiled by Levitus (1982). A restoring time constant of 20 days is used. This leads to the solution $R$, in which the overturning streamfunction associated with NADWF has a magnitude of about $12 \mathrm{~Sv}\left(\mathrm{~Sv} \equiv 1 \times 10^{6} \mathrm{~m}^{3} \mathrm{~s}^{-1}\right)$ (Fig. 2a) and zonally averaged $T$ and $S$ structure in the North Atlantic as depicted in Figs. $2 b$ and $2 c$, respectively. 
a

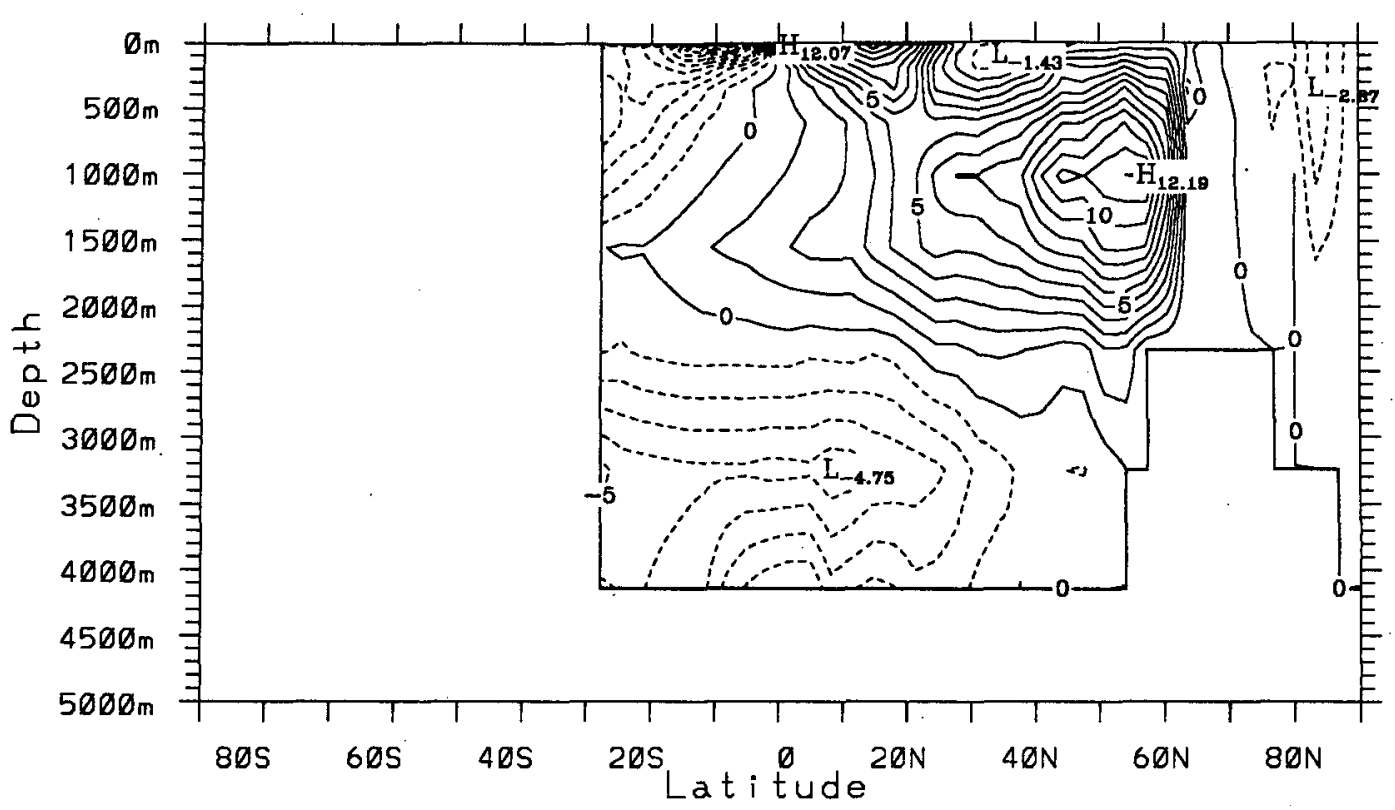

b

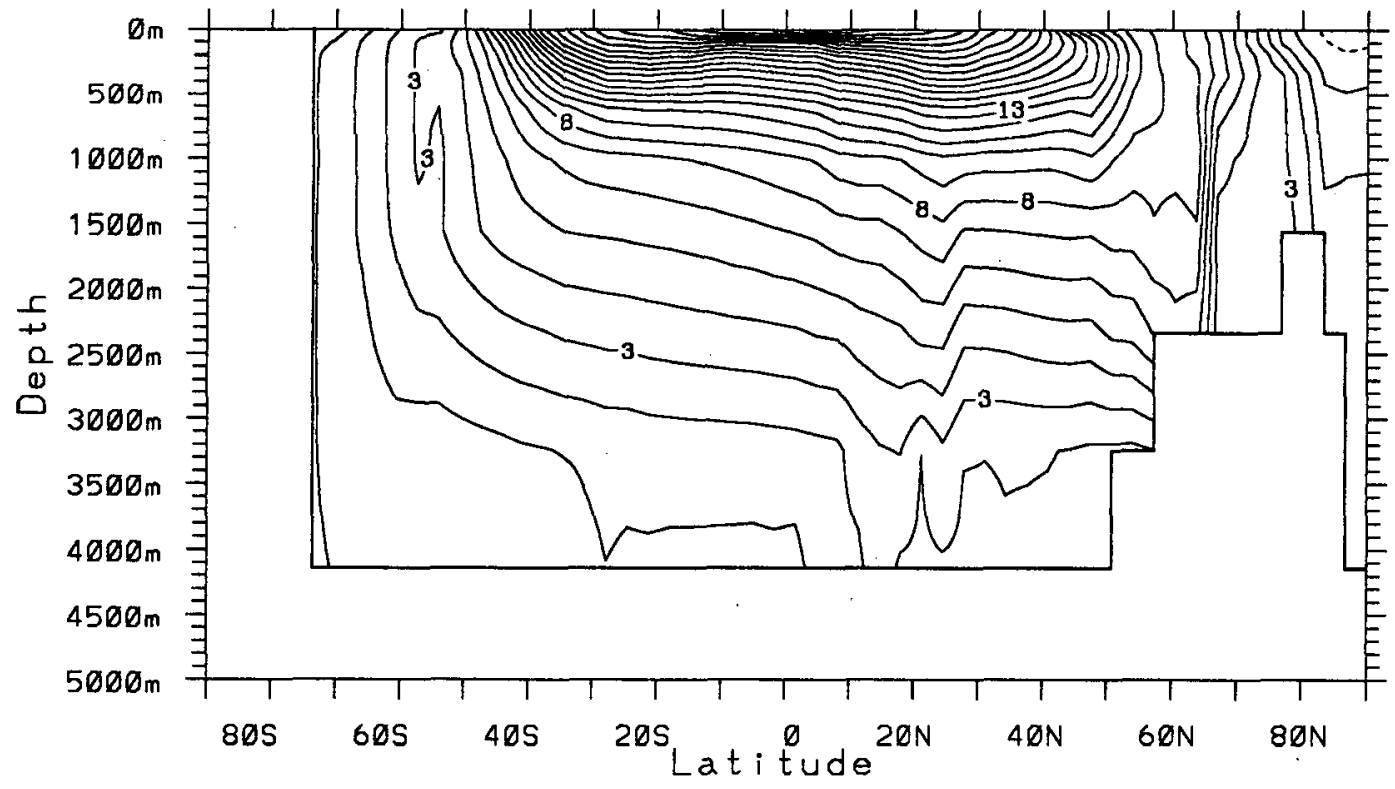

FIG. 2. The zonally averaged (a) meridional transport ( $\mathrm{Sv}$ ), (b) temperature, $T$, in degrees Celsius, and (c) salinity, $S$, over the North Atlantic (psu) under conventional restoring boundary conditions (BCs) on $T$ and $S$. A lag time of 20 days is used. This experiment is referred to as $R$ in the text.

The salt flux, $S_{F}$, is then diagnosed over a period of about 50 surface years and is presented in Fig. 3a. The wind stress, $\tau$, is kept fixed to annually averaged ob- servational estimates of Hellerman and Rosentein (1983) (as they were during $R$ ) and are presented in Fig. 3b. 
C

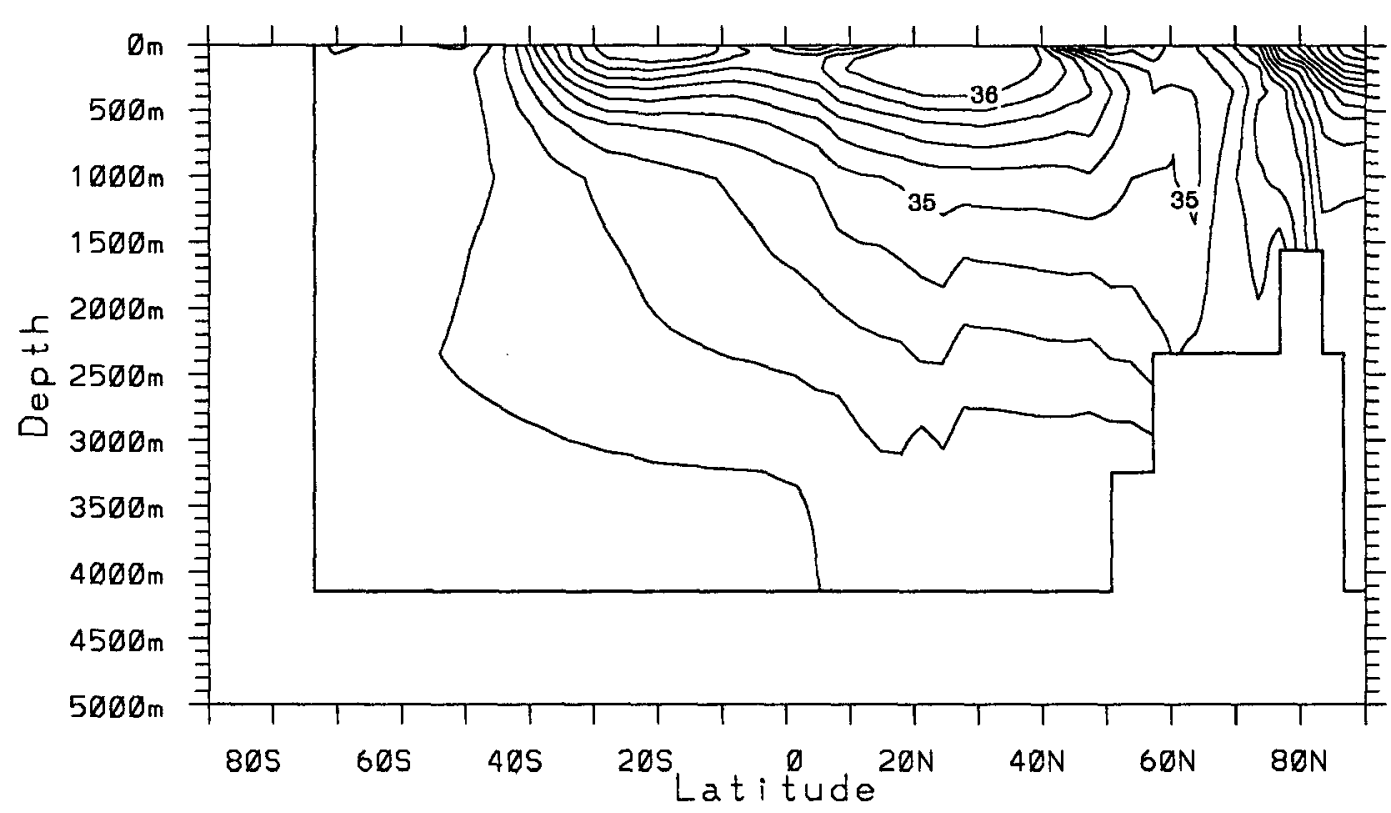

FlG. 2. (Continued)

Mixed BCs are then applied in which the salt flux is fixed to $S_{F}$ but $T$ is restored. This leads to the second solution $M$, in which the overturning has an increased magnitude of about $22 \mathrm{~Sv}$ (Fig. 4a) with horizontal, depth-averaged transports as shown in Fig. 4b. The gross underestimation of the Gulf Stream transport, for example, is a consequence of the coarse resolution used.

\section{b. The modeled GSAS}

Freshwater flux anomalies are then applied to the northern North Atlantic as shown in Fig. 5. They are applied for about 5 years. This represents an extremely crude model of the GSA. For example, the high eddy horizontal diffusivity tends to smooth the anomaly out; a number of important topographic features like Fram and Denmark Straits are missing; and the shape of the region over which the anomaly is applied is somewhat arbitrary. It does, nevertheless, provide a convenient framework in which we can address the questions raised in the introduction.

The salt deficit of the 1968-1982 GSA has been estimated to be approximately $7.2 \times 10^{13} \mathrm{~kg}$ (Dickson et al. 1988). Various anomalies are applied with salt deficits ranging from 1 (GSA1) to 24 (GSA24) times this amount and each time the meridional overturning in the northern North Atlantic associated with NADWF is diagnosed. The results are presented in Fig. 6 , in which we see that if the salt deficit is greater than or equal to about eight times that of the observational estimate a collapse ensues.

The surface salinity and temperature anomalies just after the critical anomaly (i.e., GSA8) has been applied are presented in Fig. 7. The reduction in salinity (Fig. $7 \mathrm{a}$ ) is accompanied by a drop in the surface $T$ (Fig. $7 \mathrm{~b}$ ) as a result of the reduced amount of heat convected to the surface from the deeper layers. This is evident in Fig. 7c, in which the vertical structure of anomalous $T$ is plotted along $15^{\circ} \mathrm{W}$ through the North Atlantic to a depth of $1000 \mathrm{~m}$. The temperature at depth has increased while that at the surface has decreased.

The acceleration techniques of Bryan (1984) and Bryan and Lewis (1979) were then employed to obtain the new climatology. This leg of the integration continued for 150000 tracer time steps, each 2 days long, with an acceleration factor of 8 between the surface and lowest levels. Remarkably, the overturning remained subdued at about half its original value, accompanied by weakened barotropic circulation in both the subpolar and subtropical gyres. This is evident in Fig. $8 \mathrm{a}$, in which the horizontal transports have been subtracted from the values they had prior to the imposition of the anomaly.

It is also interesting to note that there are differences in the surface heat flux between the collapsed solution and $M$ exceeding $100 \mathrm{~W} \mathrm{~m}^{-2}$ in magnitude over the North Atlantic (Fig. 8b) between $40^{\circ}$ and $60^{\circ} \mathrm{N}$.

The solution after imposing GSA8 serves as the initial conditions for most of the remaining exper- 


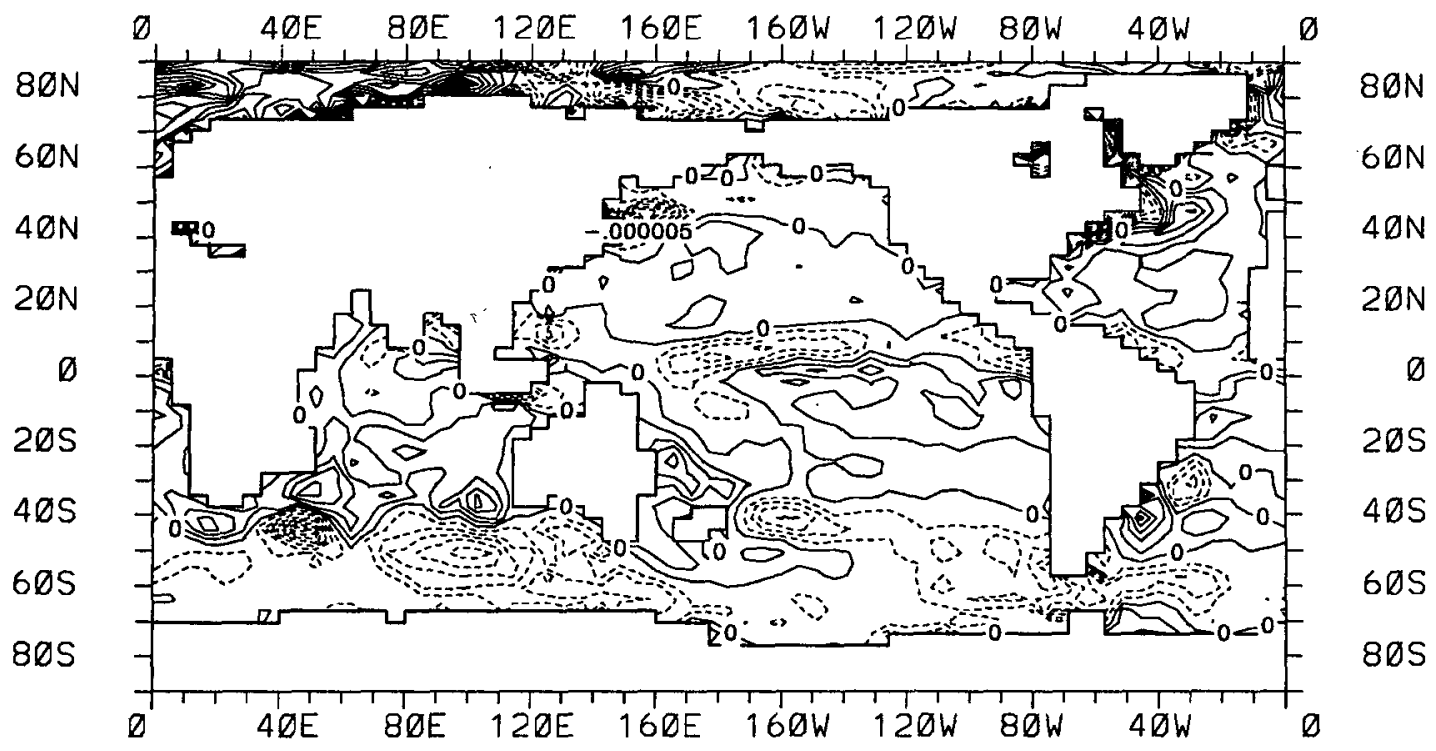

$80 N$

$60 N$

$4 D N$

$20 N$

$\emptyset$

205

$40 S$

60S

805

b

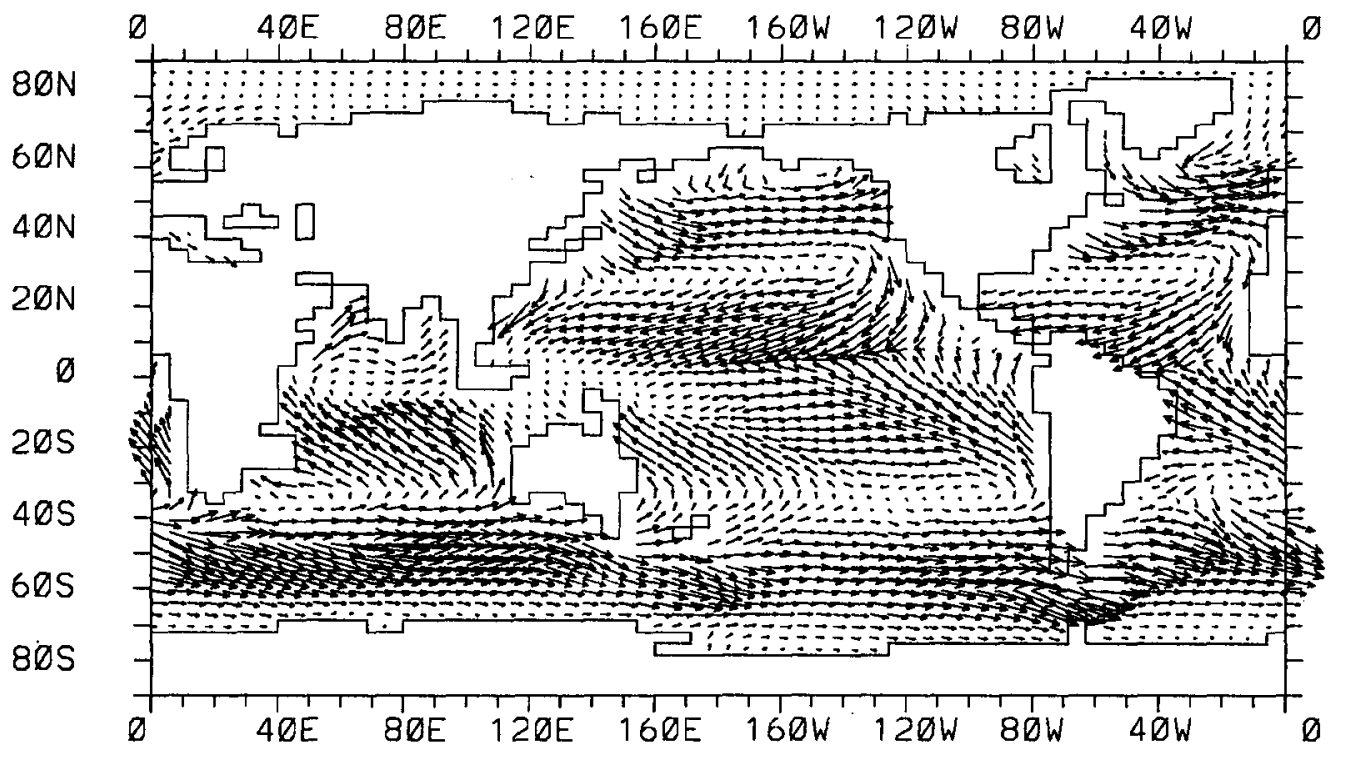

Fig. 3. The surface flux of (a) salt diagnosed from the restored solution (psu s${ }^{-1}$ ) and (b) momentum as an annual average of the observational estimates of Hellerman and Rosentein (1983).

iments conducted. These experiments differ in the way the surface fluxes of heat, salt, and momentum are parameterized. In the control experiment, for example, the parameterizations are identical to those in $M$; that is, $T$ is restored, while $S_{F}$ and $\tau$ are again fixed to the values presented in Fig. 3.

\section{c. Feedbacks}

Most of the remaining experiments presented here are designed to test whether or not the model sensitivity is dependent upon the use of mixed BCs. Some crude model feedbacks will be described that might be expected given the oceanic changes already 
a

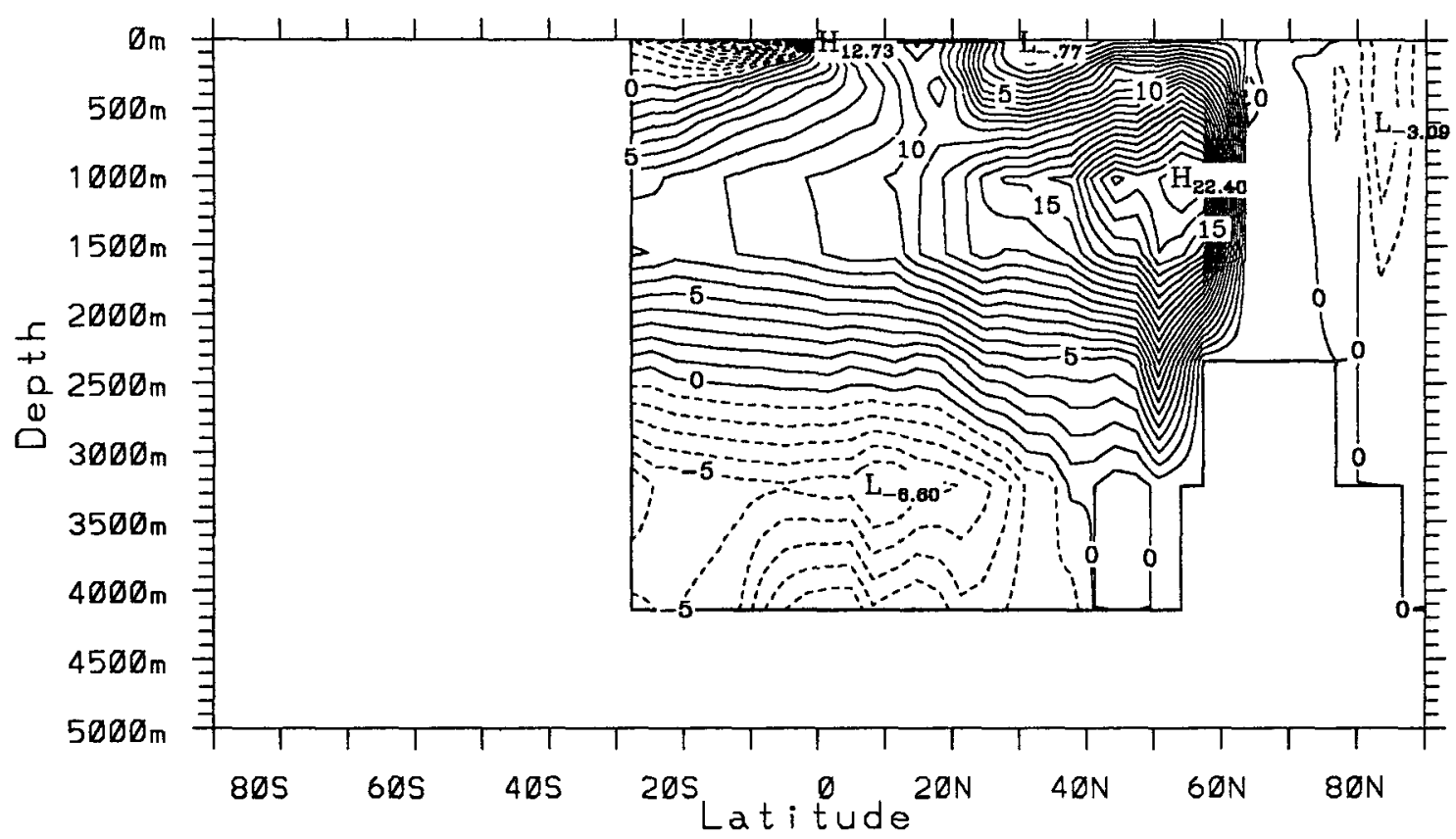

b

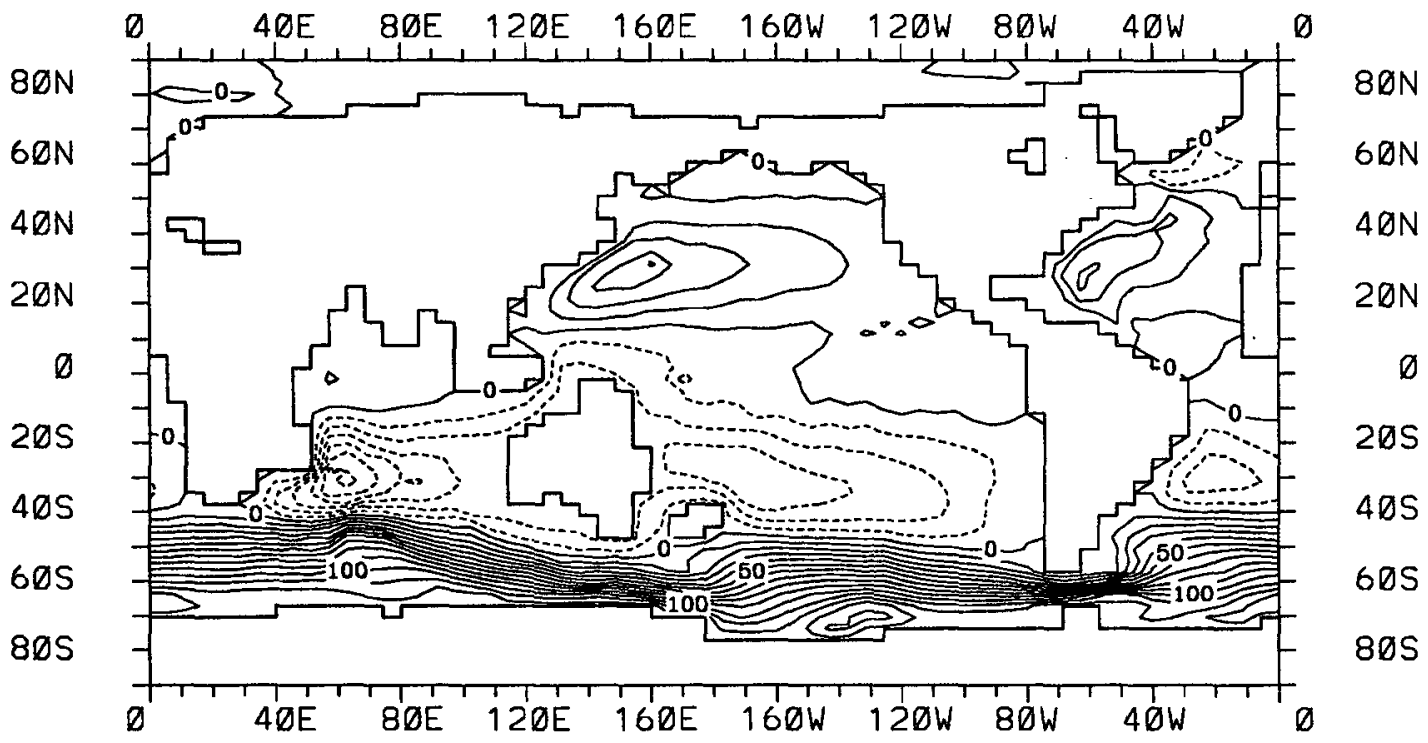

FIG. 4. The (a) zonally averaged mass transport streamfunction (or overturning) and the (b) horizontal, barotropic transport for the solution obtained under mixed BCs, that is, a restorative condition on temperature but fixed fluxes of salt and momentum. Both are in Sverdrups.

discussed, but that are absent if the usual mixed BCs are used. Feedbacks on the fluxes of momentum (subsection 1) and salt (subsection 2) will be applied and the restorative condition on $T$ will be abandoned (subsection 3 ). The last experiment will test to see if the duration over which the anomaly is 


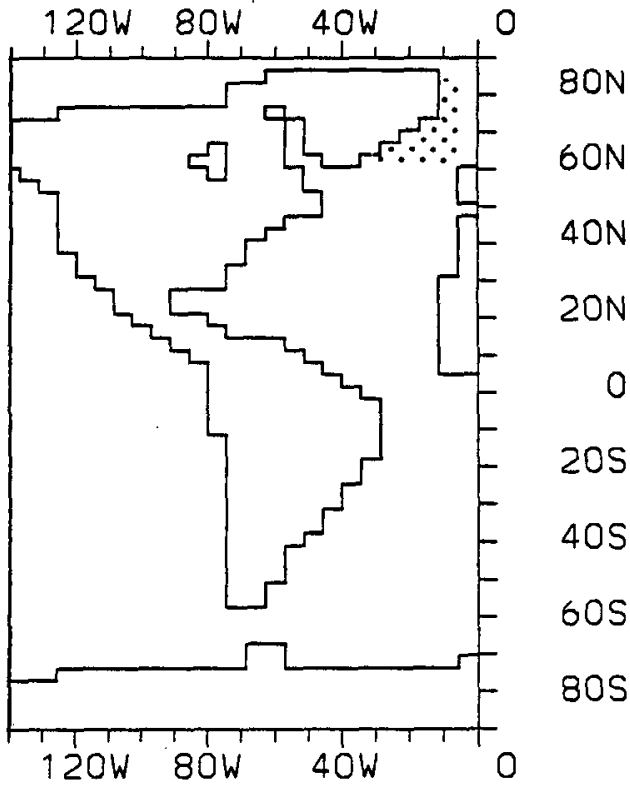

FIG. 5. The region over which the freshwater anomaly is applied.

applied is important ( section 4). Only the resulting equilibrium solutions under these feedbacks will be discussed.

\section{1) WIND STRESS}

The atmospheric circulation at midlatitudes is dominated by baroclinic disturbances, which help to maintain the surface westerlies. The thermal wind relationship shows that the meridional temperature gradient and the vertical shear are closely related. We might therefore expect that if the meridional temperature gradient is increased, then so will the activity of the disturbances, resulting in enhanced surface westerlies (see Gill 1982 for further discussion). Thus it seems reasonable to suppose that if the meridional temperature gradient is enhanced, then the surface wind stress will be increased.

To model this effect, the wind stress is parameterized as a function of the difference between the average surface temperature of the subpolar and subtropical gyres. If there is no change in this gradient, then the wind stresses retain their climatological values. The wind stress anomaly is assumed to be given by $\epsilon \tau$, where $\epsilon$ $=\alpha \Delta P(2 U+\Delta P) / U^{2}, \alpha$ is the coupling strength, $U$ $=8 \mathrm{~m} \mathrm{~s}^{-1}, \Delta P=\Delta T-\Delta T^{*}$, and $\Delta T$ is the difference between the average surface temperature of the subtropical and subpolar gyres and $\Delta T^{*}$ its value diagnosed from $M$. This formula crudely captures the qualitative features of the relationship described above-if the gradient is increased, the magnitude of the wind stress is increased.

That the gradient has increased after the imposition of GSA8 is evident in Fig. 7b. This means that under this parameterization the wind stress and its curl will be increased. This immediately results in increased Ekman flow, which soon raises the barotropic transports of both gyres but by an amount much smaller than the reduction caused by the GSA.

This simple feedback or coupled model was then integrated using various coupling strengths, and only strengths that produced wind stress anomalies up to $10 \%$ of the climatological values were considered. No attempt was made to model shifts in the wind stress field even though they might also play a significant role in determining the response. In every case considered the impact upon the overturning was minimal with only a minor adjustment evident due to the increase in the Ekman transport. A collapse in NADWF always occurred.

\section{2) Salt FlúX}

In the current climate there is a net divergence of freshwater out of the surface of the Atlantic Ocean and a net convergence into the surface of the Pacific Ocean. A large fraction of this divergence is believed to occur at midlatitudes (Broecker 1991). If the westerlies are increased then both evaporation and atmospheric water transport away from the Atlantic might also increase. If this increase exceeds any increase in the net precipitation over the same region, then the divergence from the Atlantic will also be increased. This is significant because we know that NADWF is intimately related to the divergence (Broecker 1991; Stocker and Wright 1991; Power and Kleeman 1992). As a result, we parameterize the salt flux anomaly in terms of the meridional temperature gradient discussed earlier. The anomaly is matched by a negative anomaly into the North Pacific, effectively modeling the movement of freshwater across Eurasia from the North Atlantic to

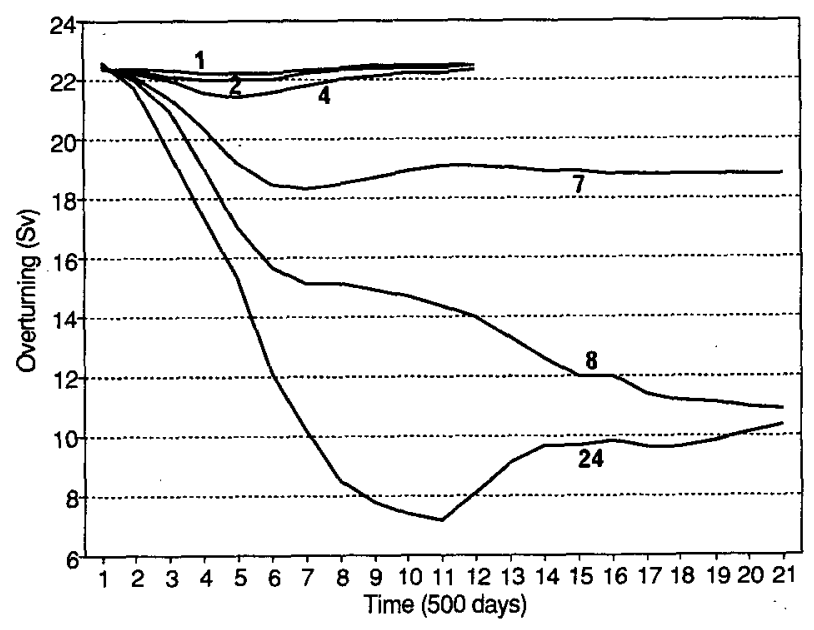

FIG. 6. The overturning (Sv) in the northern North Atlantic as a function of time for the various GSAs. Salt deficits equal to $1,2,4$, 7,8 , and 24 times that of the observed value are used. 
the North Pacific. [It could also be considered as an even cruder model of an increase in the water vapor transport across the Isthmus of Panama (Weyl 1968) from the Atlantic to the Pacific.]

Various coupling strengths are again considered, and it is found that the degree of recovery depends on this strength. In the extreme case in which the salt flux feedback amounted to about $30 \%$ of the average value of the salt flux over the North Atlantic (from $35^{\circ}$ to $50^{\circ} \mathrm{N}$ ), the overturning recovered to a value of about $12.5 \mathrm{~Sv}$, an increase of about $1.4 \mathrm{~Sv}$.

Another interesting feature of the hydrological cycle of the Northern Hemisphere is that some of the water evaporated over the North Atlantic precipitates into the catchment area of the Arctic basin and subsequently runs off. This runoff plays a dominant role in the freshwater budget of the Arctic (Aagaard and Carmack 1989). To test if the enhancement of this exchange impacts upon the overturning, the anomalous fluxes of freshwater are dumped into the Kara and Laptev Seas (in the Arctic) rather than into the North Pacific. In the extreme case the recovery amounted to about 1 $\mathrm{Sv}$, indicating that for a given freshwater transport anomaly the Atlantic-Pacific atmospheric exchange is marginally more important than the Atlantic-Arctic exchange in determining modifications to the overturning associated with NADWF. The impact of both is, however, relatively modest compared with the initial collapse.

These figures probably represent upper bounds on the restorative impact of these particular feedbacks because we have presumed that increased baroclinicity leads to a positive evaporation minus precipitation ( $E$ $-P$ ) over the North Atlantic at midlatitudes. This is supported by our estimate of the salt flux (Fig. 3a), which has a positive mean over $30^{\circ}-50^{\circ} \mathrm{N}$. If instead we had used observational estimates of $E$ (Piexoto and Oort 1983) and $P$ (Jaeger 1976), then it is possible within the large uncertainties-50\% in the case of evaporation (Piexoto and Oort 1984)-that the mean value of $P-E$ at midlatitudes actually has the opposite sign! If this is the case and we had supposed that increased baroclinicity actually reduces $E-P$, then the modest recovery would not have occurred. Indeed it would not seem unreasonable to suppose that the collapse might even have been reinforced.

As a final feedback on the salt flux, we wish to determine if the collapse of the meridional circulation occurs if a salt flux of exactly the same magnitude and duration but of opposite sign is added immediately after imposing the extreme GSA24. Remarkably, the collapse still occurs. It should be noted, however, that the overturning can be kick started in this manner if much larger and more persistent positive anomalies are imposed (Power and Kleeman 1992). It does, nevertheless, highlight the robust nature of the sensitivity of the OGCM under a restorative condition on $T$, well above the critical value of the salt deficit.

\section{3) Heat Flux}

We now wish to determine if the sensitivity is dependent upon the parameterization of the heat flux. As a crude test we simply apply BCs in which the surface fluxes of $b o t h$ salt and heat are prescribed (to values diagnosed from $M$ ) after the freshwater anomalies GSA 8 and GSA24 have been added. In both cases the final solution has a state in which overturning reaches the same level as it had prior to the GSA. Indeed, all fields, $T, S$, and the velocity, now closely approximate their pre-GSA values-the recovery is complete. Thus, the collapse is critically dependent upon the parameterization of the surface heat flux. This experiment is represented schematically in Fig. 1 as the arrow underneath the boxes marked IC (initial conditions) and $M$ (mixed BC solution).

\section{4) Duration}

In this last experiment we wish to determine if the duration of the period over which the anomaly is applied is important in determining the response. To do this a salt flux anomaly equal to half that of GSA8 is applied but for twice as long. In this case no collapse occurred.

\section{Summary and discussion}

A coarse grid version of the GFDL global OGCM (Pacanowski et al. 1991) was integrated under various upper boundary conditions (BCs) on temperature and salinity. Solutions were obtained under restoring and mixed BCs (i.e., a restoring condition on the upperlevel temperature but using a fixed, specified salt flux ).

Various freshwater anomalies were imposed over the North Atlantic subpolar gyre. This led to reduced sea surface temperatures as a result of weakened convection and a weakened barotropic circulation in both subpolar and subtropical gyres. If the salt deficit of the anomaly reached a critical value equal to about eight times that estimated for the 1968-1982 GSA (Dickson et al. 1988), the circulation collapsed to a state in which the mean meridional overturning in the North Atlantic associated with NADWF is reduced to about half the value it had prior to imposition of the anomaly. It should be noted that this value can be expected to be a function of various model parameters and the background salt flux forcing applied (Weaver et al. 1993).

The critical value was shown to be dependent upon the duration of the period over which the freshwater anomaly was imposed; that is, if the same amount of freshwater were added but over a much longer period, then the collapse will not occur. It is therefore probably more sensible to talk about a critical surface salinity or density rather than salt deficit. This is at least qualitatively consistent with the observation that convective overturn in the Iceland (Malmberg 1972) and Labrador Seas (Lazier 1980) is limited if the surface salinity falls 
a

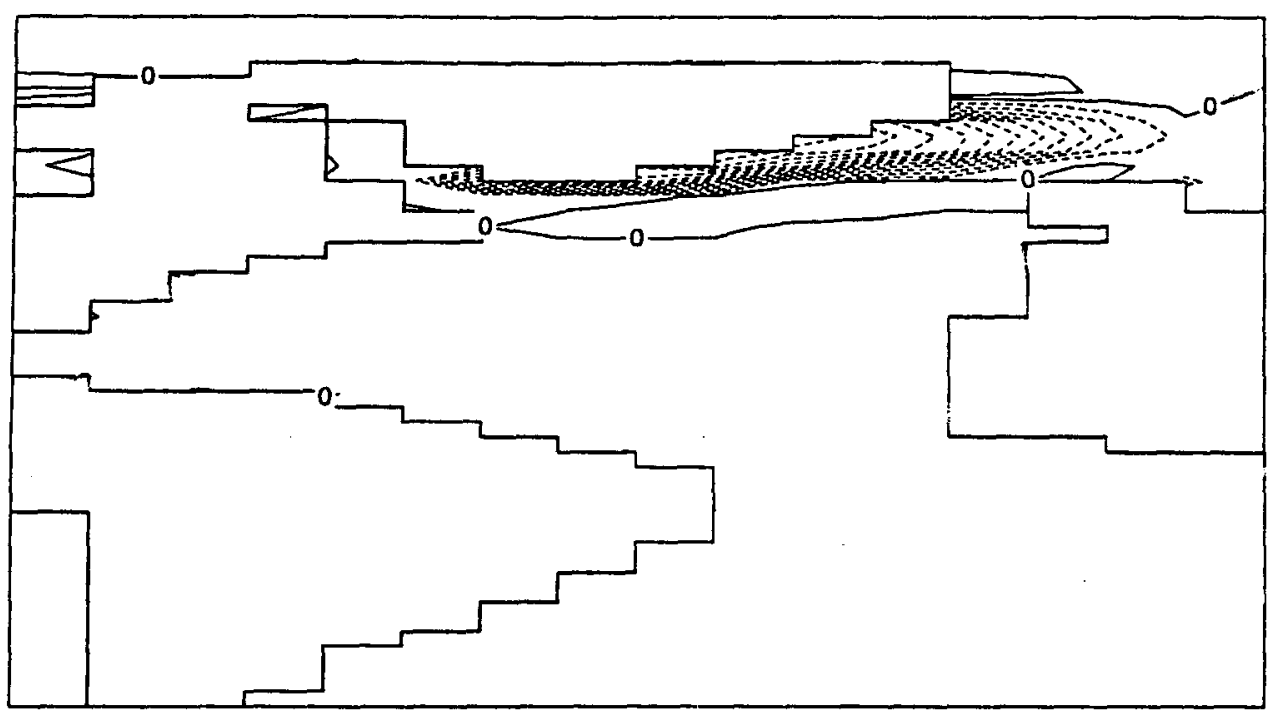

b

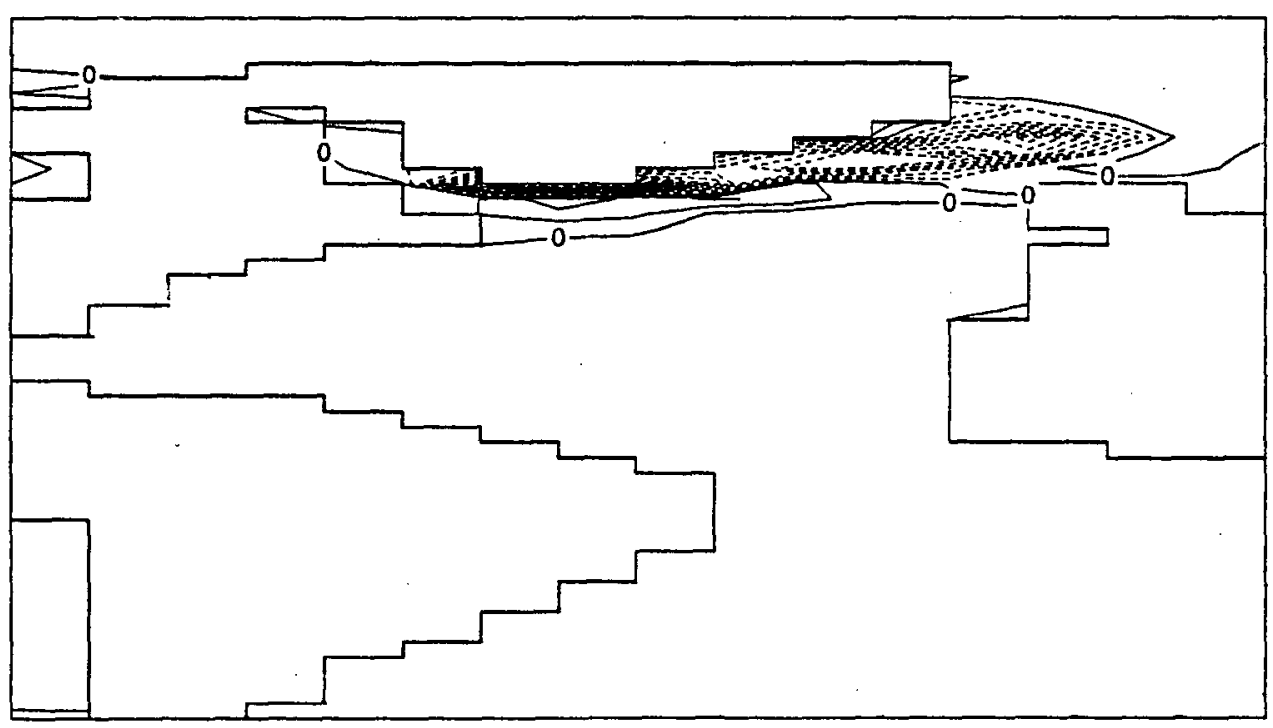

FIG. 7. The anomalies of surface (a) salinity (psu) and (b) temperature $\left({ }^{\circ} \mathrm{C}\right.$ ) and (c) a vertical section through the North Atlantic along $15^{\circ} \mathrm{W}$ of the temperature in the top $1000 \mathrm{~m}$. The solution $M$ has been subtracted from the solution just after the freshwater anomaly GSA8 has been applied. A contour interval of $0.01^{\circ} \mathrm{C}$ is used in (c).

below certain levels. The subsequent collapse of the overturning modeled here, however, is much more dramatic than anything Malmberg (1972) or Lazier (1980) observed.
The model collapse included large and sustained surface heat fluxes over the North Atlantic, so large atmospheric feedbacks should, in reality, occur. In an attempt to model these feedbacks the surface fluxes of 
C

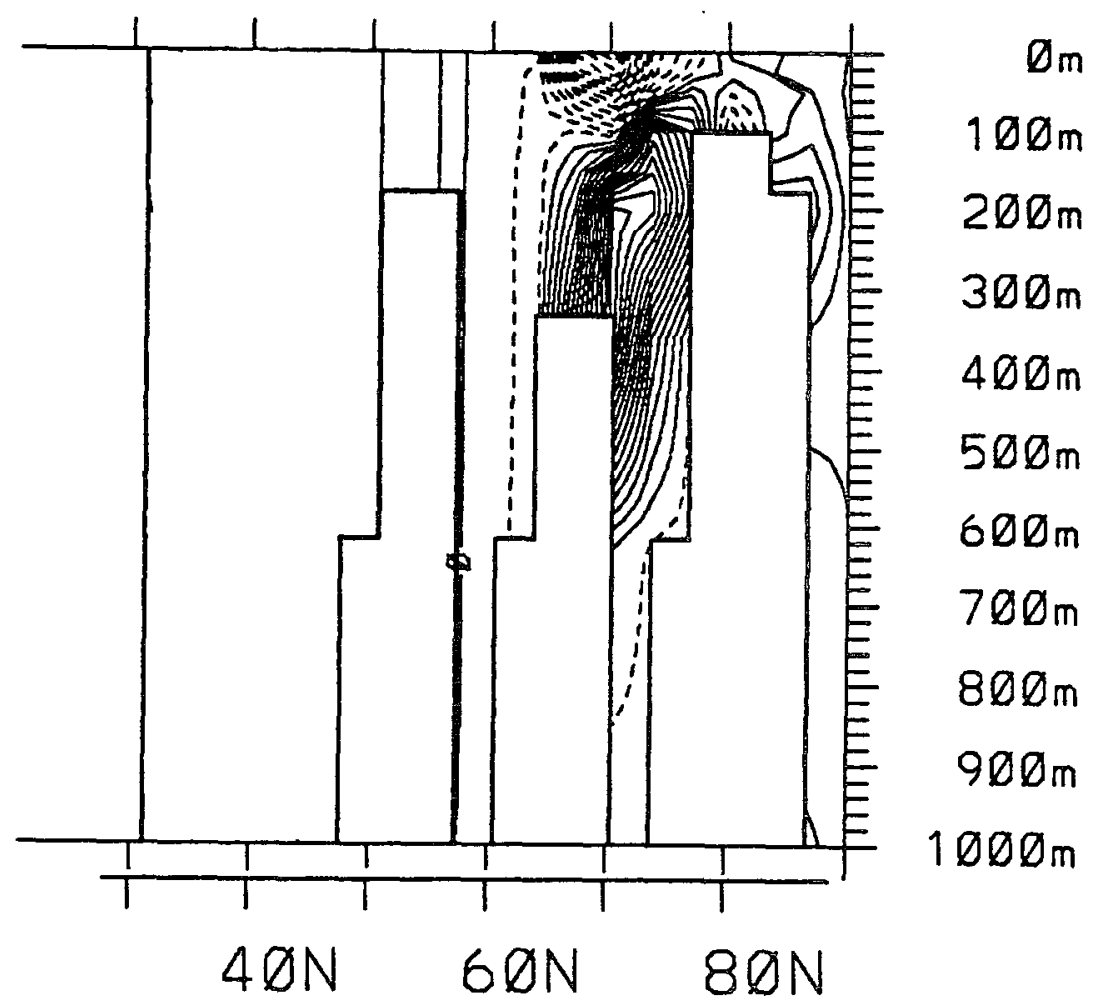

FIG. 7. (Continued)

momentum and salt were crudely parameterized in terms of the meridional gradient of sea surface temperature. It was found that increased wind stresses had very little impact upon the deeper circulation. On the other hand, a modest recovery was possible if the parameterized salt flux feedback included an enhancement of the freshwater divergence out of the Atlantic into either the Arctic or North Pacific (via the atmosphere), with the recovery greatest in the latter case.

Persistence of the collapsed state modeled was shown to be critically dependent upon the restorative condition employed on the upper-level temperature-if the condition is abandoned, then a full recovery ensues. This means that the parameterization of the heat flux is very important in studies that seek to determine the sensitivity of NADWF to given perturbations.

There are a number of reasons why the use of a restoration condition on temperature in studies of climatic change might be questioned.

(i) The apparent air temperatures and the lag times are properties of the current climate. In an alternative or evolving climate they may well be different.

(ii) The climatic state obtained here in which the overturning associated with NADWF is subdued can be regarded as an equilibrium solution of a crude coupled climate model. In this model all the nonoceanic components have infinite heat capacities so that they are not perturbed from their current climatologies by the large and sustained surface heat flux anomalies evident.

(iii) It is the ocean that provides most of the inertia for our climate, thereby helping to provide a stabilizing influence on the apparent air temperatures and lag constants used in the restoration. The ocean is, however, significantly altered in the collapsed state obtained here but this is not reflected in the heat flux parameterization. How then do we know that the simple parameterization gives reasonable values for the heat flux in the new climate or during the evolution?

The stability of NADWF to high-latitude freshwater anomalies using models that incorporate more sophisticated estimates of the surface heat flux anomalies might therefore differ from that exhibited under a restorative condition on the upper-level temperature. Realistic coupled atmosphere-ice-ocean GCMs rather than OGCMs under mixed BCs are therefore required to properly assess the stability. 


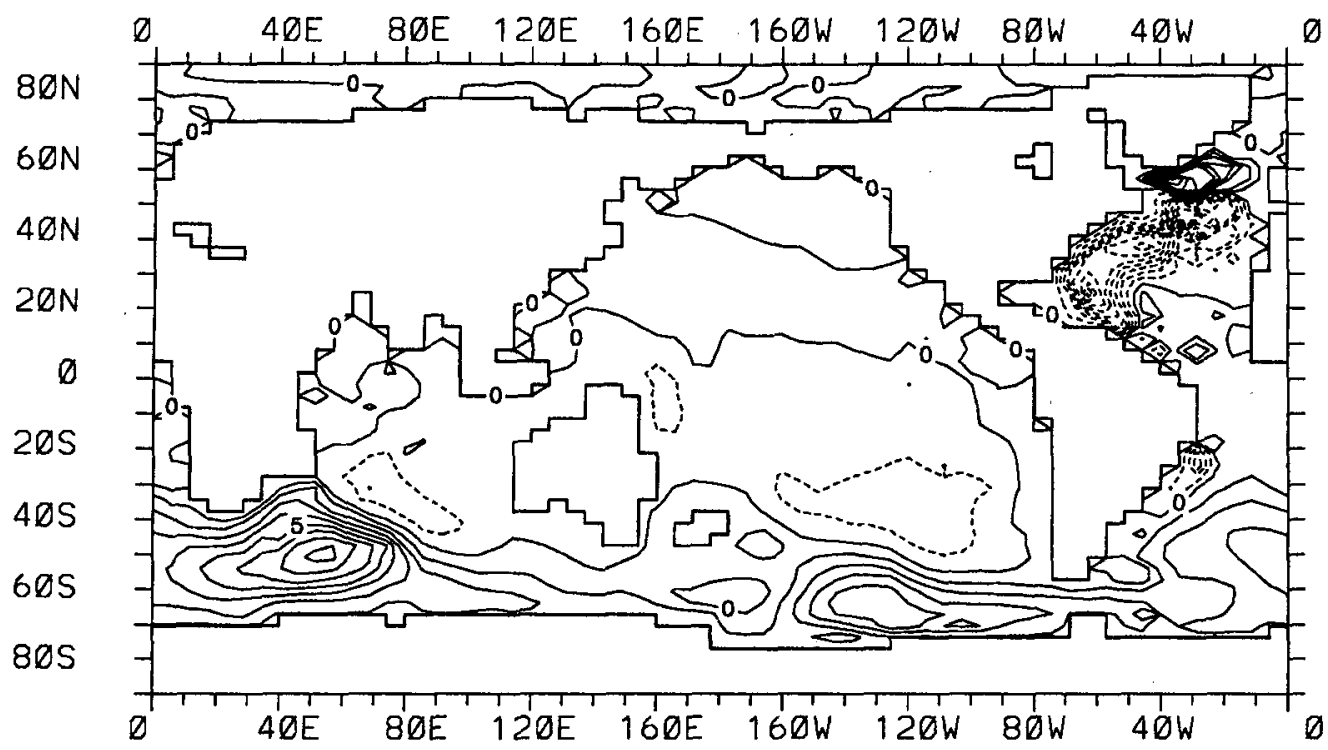

$80 N$

$60 \mathrm{~N}$

$40 \mathrm{~N}$

$20 N$

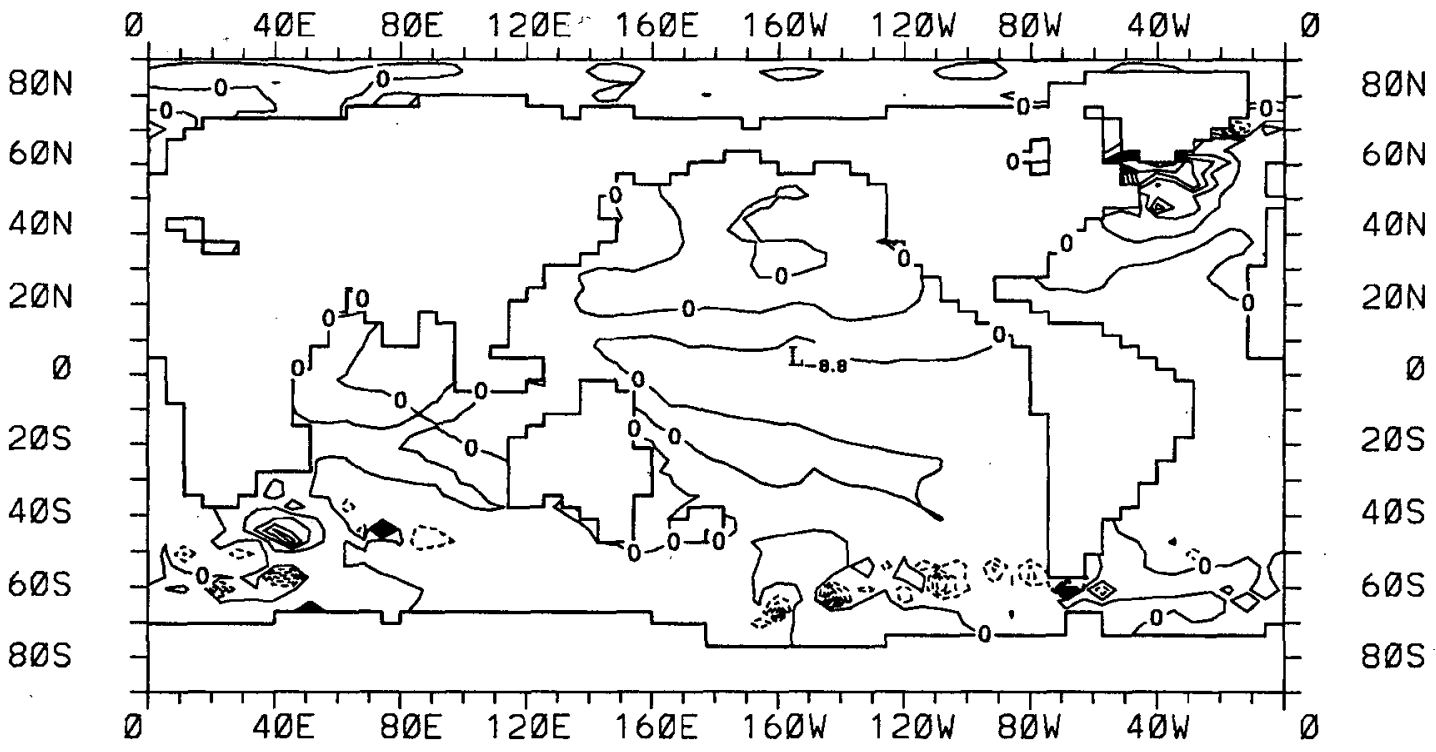

FIG. 8. The anomalies of the (a) barotropic transport (Sv) and (b) surface heat flux $\left(25 \mathrm{~W} \mathrm{~m}^{-2}\right)$ in the collapsed equilibrium state obtained by extended (and accelerated) integration after GSA8 was imposed.

Progress toward this goal has already begun: Manabe and Stouffer (1988) found that two stable states could exist in their fully coupled atmosphere-ocean GCM, one with NADWF $\left(\mathrm{MS}_{1}\right)$ and one without $\left(\mathrm{MS}_{2}\right)$. So while we have been skeptical about the applicability of the restorative condition on $T$ in a fundamentally dif- ferent climate, the existence of $\mathrm{MS}_{2}$ in their model provides supporting evidence to the contrary. More research is obviously required.

Manabe and Stouffer (1988) also found that $\mathrm{MS}_{2}$ could not be made to form NADW if the salt flux diagnosed from MS, was applied, highlighting the sta- 
bility of this second climate. Under the alternative view (i.e., that the restoring condition is adequate in the new state) the results obtained here (and by Power and Kleeman 1992) would suggest that it is the heat flux in their model that is largely responsible for the stability.

A coupled model is currently being developed here at BMRC, and it is hoped that this model will be used to conduct these and other experiments aimed at assessing the climatic response to various perturbations including high-latitude freshenings. It is important to realize, however, that this model will be no different to the current generation of such models in the sense that flux correction will be required if we wish to suppress substantial climatic drift. This drift occurs in the absence of any imposed perturbation as a result of systematic model errors (Manabe and Stouffer 1988; Sausen et al. 1988; Meehl 1992). As a result of these errors we will have to follow Manabe and Stouffer's (1988) lead by treating any subsequent conclusions based on the corrected model with caution.

Finally, we note that Zhang et al. (1993) have performed related experiments using a simple quasigeostrophic thermocline model (Zhang et al. 1992) consisting of a single flat-bottomed basin. It is reassuring to note that they also found that the sensitivity of their model was dependent upon how the heat flux is parameterized.

Acknowledgments. An older version of the GFDL code used here was modified by Wenju Cai, Tony Hirst, Andy Moore, and David Post at CSIRO. These modifications were then incorporated into the MOM code by DAP, SBP, and AMM. SBP wishes to thank Andrew Weaver and Lawrence Mysak for introducing him to mixed BCs and the GSA, respectively, and Terry Hart for reviewing an earlier draft.

\section{REFERENCES}

Aagaard, K., and E. C. Carmack, 1989: The role of sea ice and other freshwater in the Arctic circulation. J. Geophys. Res., 94, 14 48514498.

Broecker, W. S., 1991: The great conveyor belt. Oceanography, 4, 79-89.

- D. M. Peteet, and D. Rind, 1985: Does the ocean-atmosphere system have more than one stable mode of operation? Nature, $315,21-26$.

Bryan, F., 1986: High-latitude salinity effects and interhemispheric thermohaline circulations. Nature, 323, 301-304.

Bryan, K., 1969: A numerical method for the study of the circulation of the world ocean. J. Comput. Phys., 4, 347-376.

$\longrightarrow$ 1984: Accelerating the convergence to equilibrium of oceanclimate models. J. Phys. Oceanogr., 14, 666-673.

- - and L. J. Lewis, 1979: A water mass model of the world ocean. J. Geophys. Res., 84, 347-376.

Cox, M. D., 1984: A primitive equation, 3-dimensional model of the ocean. GFDL Ocean Group Tech. Rep. No. 1, GFDL/Princeton University.

Dickson, R. R., H. H. Lamb, S.-A. Malmberg, and J. M. Colebrook, 1975: Climatic reversal in northern North Atlantic. Nature, 256, 479-482.

- J. Meincke, S.-A. Malmberg, and A. J. Lee, 1988: The Great Salinity Anomaly in the northern North Atlantic 1968-1982. Progress in Oceanography, Vol. 20, Pergamon, 103-151.
Gill, A. E., 1982: Atmosphere-Ocean Dynamics. Academic Press, $662 \mathrm{pp}$.

Greatbatch, R. J., Fanning, A. F., Goulding, A. D., and S. Levitus, 1991: A diagnosis of interpentadal changes in the North Atlantic. J. Geophys. Res., 97, 22 009-22 024.

Haney, R. L., 1971: Surface thermal boundary conditions for ocean circulation models. J. Phys. Oceanogr., 4, 241-248.

Hellerman, S., and M. Rosenstein, 1983: Normal monthly wind stress over the World Ocean with error estimates. J. Phys. Oceanogr., 13, 1093-1104.

ICSUSCO, 1991: World Ocean Circulation Experiment. Intergovernmental Ocean. Comm., World Meteorological Organization, World Climate Research Programme, 31 pp.

Jaeger, L., 1976: Monthly precipitation maps for the whole earth. Ber. Dtsch. Wetterdienstes, 139, 33 pp.

Lazier, J. R. N., 1980: Oceanographic conditions at Ocean Weather Ship Bravo, 1964-1974. Atmos.-Ocean, 18, 227-238.

Levitus, S., 1982: Climatological Atlas of the World Ocean. NOAA Prof. Paper No. 13, 173 pp.

Maeier-Reimer, E., and U. Mikolajewicz, 1989: Experiments with an OGCM on the cause of the Younger Dryas. Oceanography. UNAM Press, 87-100.

Malmberg, S.-A., 1972: Annual and seasonal hydrographic variations in the East Icelandic Current between Iceland and Jan Mayen. Sea Ice, National Research Council Reykjavik, 42-54.

Manabe and Stouffer, 1988: Two stable equilibria of a coupled oceanatmosphere model. J. Climate, 1, 841-866.

Marotzke, J., 1989: Instabilities and steady states of the thermohaline circulation. Ocean Circulation Models: Combining Data and Dynamics. D. L. T. Anderson and J. Willebrand, Eds., Kluwer, $501-511$.

Meehl, G. A., 1992: Global coupled models: atmosphere, ocean, sea ice. Climate System Modeling, K. E. Trenberth, Ed., Cambridge University Press, $788 \mathrm{pp}$.

Moore, A. M., and C. J. C. Reason, 1993: The response of a global OGCM to climatological surface boundary conditions for temperature and salinity. J. Phys. Oceanogr., 23, 300-328.

Mysak, L. A., and S. B. Power, 1991: Greenland sea ice and salinity anomalies and interdecadal climate variability. Climatol. Bull., 25, 81-91.

- D. K. Manak, and R. F. Marsden, 1990: Sea-ice anomalies observed in the Greenland and Labrador Seas during 19011984 and their relation to an interdecadal Arctic climate cycle. Climate Dyn., 5, 111-133.

Pacanowski, R. C., Dixon, K., and A. Rosati, 1991: The GFDL Modular Ocean Model users guide. Version 1.0. GFDL Ocean Group Tech. Rep. No. 2.

Peixoto, J. P., and A. H. Oort, 1983: The atmospheric branch of the hydrological cycle and climate. Variations of the Global Water Budget, Reidel.

- - and - 1984: Physics of climate. Rev. Modern Phys., 56(3), $365-429$.

Power, S. B., and R. Kleeman, 1992: Multiple equilibria in a global ocean general circulation model. J. Phys. Oceanogr., 23, 16701681.

Sausen, R., R. K. Barthels, and K. Hasselman, 1988: Coupled oceanatmosphere models with flux correction. Climate Dyn., 2, 154163.

Semtner, A. J., and R. M. Chervin, 1988: A simulation of the global ocean circulation with resolved eddies. J. Geophys. Res., 93(C12), $15502-15522$.

Stocker, T. F., and D. G. Wright, 1991: A zonally averaged ocean model for the thermohaline circulation. Part II: Interocean circulation in the Pacific-Atlantic basin system. J. Phys. Oceanogr., 21, 1725-1739.

__ _ _ - and L. A. Mysak, 1992: A zonally averaged coupled ocean-atmosphere model for paleoclimatic studies. J. Climate, 5, 773-797.

Walsh, J. E., and W. L. Chapman, 1990: Arctic contribution to upperocean variability in the North Atlantic. J. Climate, 3, 14621473. 
Weaver, A. J., J. Marotzke, P. F. Cummins, and E. S. Sarachik, 1993: Stability and variability of the thermohaline circulation. J. Phys. Oceanogr., 23, 39-60.

Weyl, P. K., 1968: The role of the oceans in climatic change: A theory of the ice ages. Causes of Climate Change, Meteor. Monog., No. 30, Amer. Meteor. Soc., 37-62.

Wright, D. G., and T. F. Stocker, 1991: A zonally averaged ocean model for the thermohaline circulation. Part I: Model development and flow dynamics. J. Phys. Oceanogr., 21, 1713-1724.

Zhang, S., C. A. Lin, R. J. Greatbatch, 1992: A thermocline model for ocean climate studies. J. Mar. Res., 50, 99-124.

- R. J. Greatbatch, C. A. Lin, 1993: A reexamination of the polar halocline catastrophe and implications for coupled oceanatmosphere modeling. J. Phys. Oceanogr., 23, 287-299. 